\title{
S.O.S. Rhino, by C. A. W. Guggisberg. Deutsch, 27s. 6d.
}

This book documents the sad story of the decline of the rhinoceroses, sacrificed in part to the demand for their horn in pursuit of the elusive El Dorado of sexual pleasure. Firstly, the three Asian species were all but exterminated, and then the sun of rhinoceros fortune started to sink at an unbelievable speed in the west, as the traders looked to Africa. Coupled with loss of habitat, and exacerbated by big game hunting, poaching activities have reduced both black and white species to but a vestige of their former glory.

Of the six chapters in this book two are devoted to the black and white rhinos of Africa; the three Asian species, about which less is known share a single chapter. Every detail of their life histories and relationships to other species, particularly man, is included; even the plants taken for food, and rhino parasites are listed. The author is obviously a keen rhino watcher, and many of his field observations, for example, of the turbulent pre-copulatory behaviour of black rhinos, must surely make a valuable addition to our knowledge. There is also an eminently readable account of the 60-million-year history of the rhinoceros family, and a chapter entitled 'Rhinos and Man' is a compendium of rhino lore, a subject with which the author is obviously as much at home as with natural history. This book must be read by all conservationists. Because of the sensitive writing one closes it with a greater appreciation of these fine mammals, and with a feeling of despondency about the folly of man. However, Mr Guggisberg has his feet firmly planted on the ground, and leaves us in no doubt about the problems of maintaining the stocks of rhinos, particularly the Asian. He makes a timely plea for good sense.

\section{JOHN SPARKS}

\section{The Mammals of Rhodesia, Zambia and Malawi, by R. H. N.}

Smithers. Illustrated by E. J. Bierly. Collins, 25s.

Although unlikely to rival their avian counterparts in number, it is pleasing that several popular books on African mammals have been forthcoming in the past few years. This one sets out to provide the general reader in Rhodesia, Zambia and Malawi with the means of recognition of such mammals as he is likely to encounter, mainly during visits to wildlife areas, though in some cases in the course or normal day to day travelling, and it succeeds admirably. Primates, carnivores, ant-bear, pangolins, dassies, elephants and even the odd-toed ungulates found in the area, plus several selected species of the lesser known small mammals, are described, with concise notes on distribution, habitat, habits, diet, breeding and miscellaneous points. Subspecific names have rightly been omitted; they are of real interest only to the specialist, and often confusing to the layman, though they can be of considerable importance from the conservation angle. The text is supplemented where necessary by silhouettes of spoor taken from clay casts of the feet of fresh specimens, and also by individual range maps, which come out surprisingly well considering the small scale, though, as the author points out, knowledge of distribution is still often incomplete. A few records have been overlooked-for example the mongooses Helogale parvula and Paracynictis selousi have now been confirmed from Malawi, and the red duiker Cephalophus natalensis has been recorded from the south of that country, though there is no recent record. There is a short, well chosen bibliography, and separate indexes of colloquial and scientific names. 